\section{Effects of Frequency and Duty Ratio on the Growth of Potato Plantlets In Vitro Using Light-emitting Diodes}

\author{
Ruey-Chi Jao ${ }^{1}$ \\ Department of Information Management, Chien Kuo Institute of Technology, \\ No. 1, Jieshou N. Rd., Changhua City, Taiwan, 500, R.O.C. \\ Wei Fang ${ }^{2}$ \\ Department of Bio-Industrial Mechatronics Engineering, National Taiwan \\ University, No. 1, Sec. 4, Roosevelt Rd., Taipei, Taiwan, 106, R.O.C.
}

Additional index words. frequency, duty ratio, photosynthesis, controlled environment

\begin{abstract}
Effects of intermittent light on photomixotrophic growth of potato plantlets in vitro and the electrical savings that could be realized by adjusting the frequency and duty ratio of light-emitting diodes (LEDs) were investigated and compared to the use of conventional tubular fluorescent lamps (TFLs). TFLs provide continuous fluctuating light at $60 \mathrm{~Hz}$ and LEDs provide continuous nonfluctuating or intermittent/pulse light depend on the preset frequency and duty ratio. In total, eight treatments were investigated with varying light source, frequency, duty ratio and photoperiod. Results indicated that if growth rate is the only concern, LEDs at $720 \mathrm{~Hz}$ [1.4 milliseconds (ms)] and 50\% duty ratio with 16-h light/8-h dark photoperiod stimulated plant growth the most. However, if energy consumption is the major concern, using LEDs at $180 \mathrm{~Hz}(5.5 \mathrm{~ms})$ and $50 \%$ duty ratio with 16-h light/8-h dark photoperiod would be the best choice for illuminating potato plantlets without significantly sacrificing plant growth, especially when energy for heat removal is also considered.
\end{abstract}

Experiments on photosynthesis in intermittent light began in the early 20th century. Brown and Escombe (1905) used a rotating segmented wheel to reduce irradiance by $25 \%$ without altering the spectral quality and rate of photosynthesis. Use of intermittent irradiation was proposed to increase yields, fasten growth rates, or both (Emerson and Arnold, 1932; Rabinowitch, 1956; Warburg, 1919).

The duty ratio of intermittent light is defined as the ratio between the duration of light-on $\left(\mathrm{T}_{\mathrm{H}}\right)$ to the total light-on plus light-off $\left(\mathrm{T}_{\mathrm{L}}\right)$ period (Fig. 1). Warburg (1919) found that the oxygen yield of Chlorella per amount of light was improved $10 \%$ to $100 \%$ by providing intermittent light, four periods per minute $(0.067 \mathrm{~Hz})$ at $50 \%$ duty ratio $\left(\mathrm{T}_{\mathrm{H}}=\mathrm{T}_{\mathrm{L}}=7.5 \mathrm{~s}\right)$ and 8000 periods per minute $(133 \mathrm{~Hz})$ at $50 \%$ duty ratio $\left[\mathrm{T}_{\mathrm{H}}=\mathrm{T}_{\mathrm{L}}=3.75\right.$ milliseconds $\left.(\mathrm{ms})\right]$, respectively, over continuous light. Emerson and Arnold (1932) observed a 400\% increase in yield of photosynthetic oxygen per amount of light when Chlorella pyrenoidosa were illuminated at 50 flashes per second $(50 \mathrm{~Hz}$; $20 \mathrm{~ms})$ and duty ratio of $17 \%\left(\mathrm{~T}_{\mathrm{H}}=3.4 \mathrm{~ms}\right.$, $\mathrm{T}_{\mathrm{L}}=16.6 \mathrm{~ms}$ ). In the same experiment, they also found that at $25^{\circ} \mathrm{C}$, the $\mathrm{O}_{2}$ flash yield was independent of $\mathrm{T}_{\mathrm{L}}$ over the available range of 35 to $425 \mathrm{~ms}$. While at $11^{\circ} \mathrm{C}$, the $\mathrm{O}_{2}$ flash yield increased with $\mathrm{T}_{\mathrm{L}}$, asymptotically approaching the same yield observed for $\mathrm{T}_{\mathrm{L}}=425 \mathrm{~ms}$ at $25^{\circ} \mathrm{C}$. However, the improvement of yield

Received for publication 22 Apr. 2002. Accepted for publication $24 \mathrm{Feb} .2003$.

${ }^{1}$ Assistant Professor.

${ }^{2}$ Professor. To whom reprint requests should be sent

E-mail: weifang@ntu.edu.tw in lettuce production was not observed using high frequency $(37 \mathrm{kHz})$ fluorescent lamps compared with regular $(60 \mathrm{~Hz})$ florescent lamps (Hashimoto et al., 1988).

Tennessen et al. (1995) used a different approach in studying efficiency of continuous and intermittent light. They used LEDs to study the effects of light pulses ( $\mu$ s to ms) on photosynthesis of intact tomato leaves. The light response of photosynthesis was measured in continuous light and compared to the same total photon flux delivered in intense pulses lasting just $1 \%$ of the time. They found that photosynthetic output was similar during light pulses and continuous light $\left(50 \mu \mathrm{mol} \cdot \mathrm{m}^{-2} \cdot \mathrm{s}^{-1}\right.$ photons) treatments. However, when light/dark pulses were lengthened to $2 \mathrm{~ms}$ of light and $198 \mathrm{~ms}$ dark, net photosynthesis was reduced to half that measured in continuous light. They concluded that plants use intermittent light (in $\mathrm{kHz}$ frequencies) only as good as they use continuous light. Lengthening the dark period from 3.8 to $16.6 \mathrm{~ms}$ improved yield by $300 \%$ (Emerson and Arnold, 1932). This trend con-
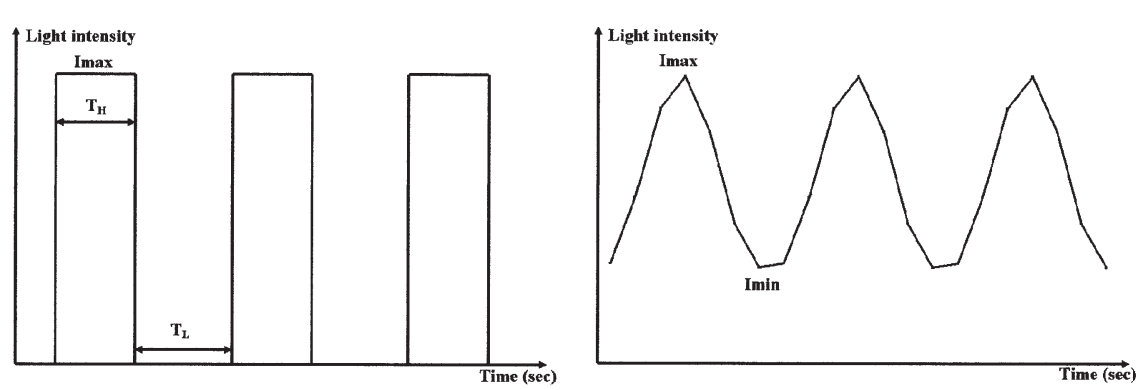

Fig. 1. Intermittent light (left) and fluctuating light (right). $\mathrm{T}_{\mathrm{H}}$ and $\mathrm{T}_{\mathrm{L}}$ mean the light on and off durations, respectively. $\mathrm{I}_{\max }$ and $\mathrm{I}_{\min }$ mean the maximum and minimum light intensity for fluctuating light. tinued until there was extra time remaining in the dark period with no intermediate products formed in previous light flash to be removed. A proper length of dark period is important to get the best yield out of a light flash of given intensity and duration. Emerson and Arnold (1932) found that at $25^{\circ} \mathrm{C}$, a dark period of 40 ms was "adequate for the complete removal of the material remaining at the end of each light flash." The same reason can be used to explain why light/dark pulses lengthened to $2 \mathrm{~ms}$ of light and $198 \mathrm{~ms}$ dark reduced the net photosynthesis as observed by Tennessen et al. (1995).

A review of the literature and reevaluation of published data on the relative photosynthetic efficiency of intermittent and continuous light was conducted by Sager and Giger (1980). They reanalyzed data of 14 published experiments using a method introduced by Weller and Franck (1941) and discussed that discrepancies regarding photosynthetic efficiency of intermittent light and continuous light were caused by incomplete or inappropriate data analysis. Misinterpretation of light utilization efficiency from the literature was also mentioned by Tennessen et al. (1995). Light distribution efficiency of intermittent vs. continuous irradiation was found to be dependent on plant type, leaf area index, and spectral quality of the irradiation (Sager et al., 1980). Nedbal et al. (1996) suggested that the photosynthetic rate should be defined as a function of the frequency, light : dark ratio and mean irradiance.

The objectives of this study were to investigate the effects of intermittent light on the photomixotrophic growth of potato plantlets in vitro and on the possibility of electricity savings by adjusting the frequency and duty ratio of previously developed artificial light source.

\section{Materials and Methods}

Descriptions of the lighting system. Two artificial lighting systems were used in this study. An apparatus made of nine super bright red (HLMP-EG08-VY000, HP, Miami) and four blue (HLMP-CB16, HP) LEDs providing a peak wavelength of red $(645 \mathrm{~nm})$ and blue $(460 \mathrm{~nm})$ (Fig. $2 \mathrm{~A}$ and B) was constructed. Cool-white tubular fluorescent lamps (TFLs) (FL48D/38, TFC Corp., Taiwan) with peak wavelength of red $(600 \mathrm{~nm})$ and blue $(452 \mathrm{~nm})$ were used as the control treatment (Fig. 2C). Relative spectral photon output distributions of fluorescent lamp and LEDs were determined 

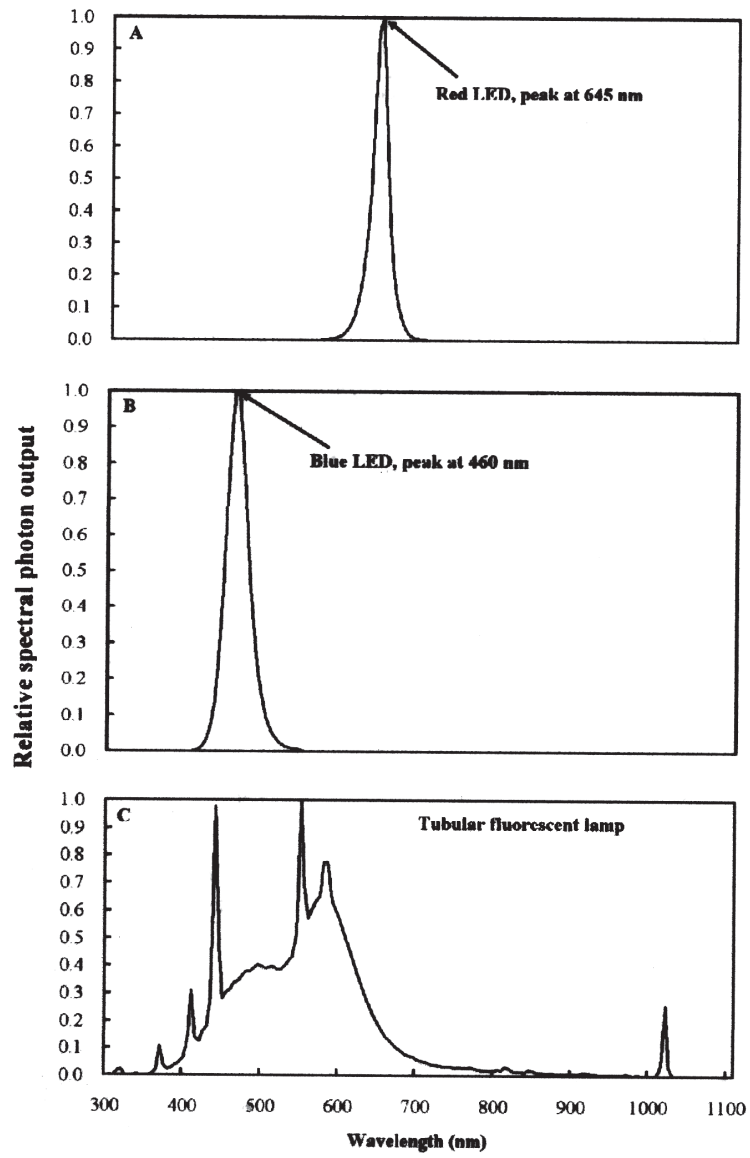

Fig. 2. Relative photon output of super bright red (A) and blue (B) LEDs and tubular fluorescent lamp (C).
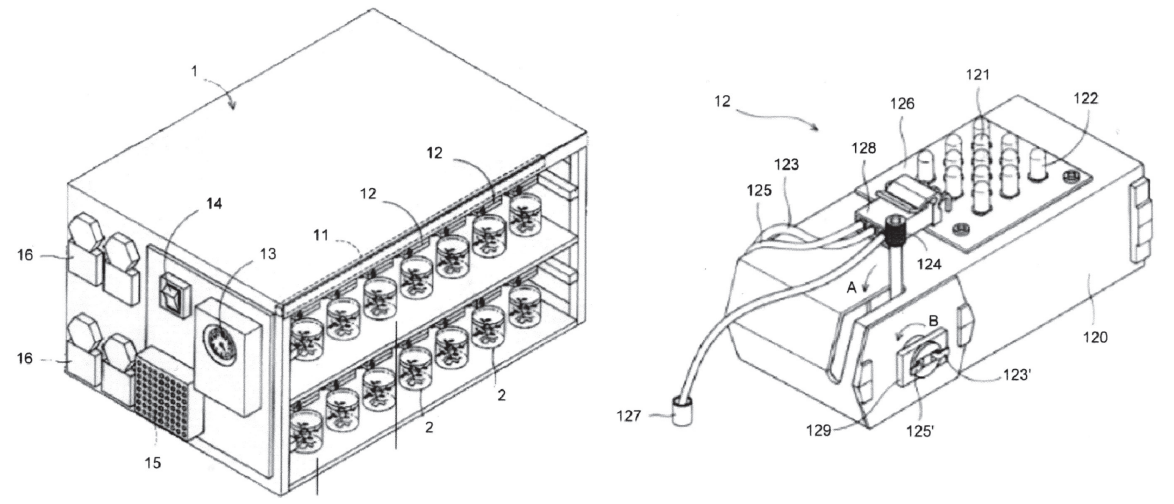

Fig. 3. Experimental setup of LEDSets (12) on top of the cultural vessels (2) with potato plantlets. 2: culture vessel, 11: electric track, 12: LEDSet, 13: timer for photoperiod, 14: power switch, 15: AC/DC converter, 16: LEDSet driver, 120: plastic electrical box, 121: blue LEDs, 122: red LEDs, 123 and 123': power line of red LEDs, 124: rotator for connecting to 11, 125 and 125': power line of blue LEDs, 126: circuit board, 127: common ground line of 123 and 125, 128: connecter.

using a LI-COR LI-1800 (LI-1800, LI-COR, Lincoln, Nebr.).

The apparatus used in LED treatments, termed LEDSet (Fig. 3), was a plastic electrical box with LEDs attached and powered with a 5-V DC converted from $110 \mathrm{~V} \mathrm{AC} \mathrm{(Jao}$ and Fang, 2001). At most, 10 LEDSets were attached on a three-wire electric track, modified from a commercially available two-wire electric track. A control-driver was required for each electric track. The LEDSet consisted of an electrical box and a circuit board on the box. Nine red-LEDs and four blue-LEDs were alternately mounted on the circuit board and spaced $1 \mathrm{~cm}$ apart for the same type of LEDs (Jao and Fang, 2001, 2003).

Red and blue LEDs require different driving voltages, with a common ground, totaling three wires to supply power. The red and blue LEDs were connected to three wires through the circuit board and connector, wherein two wires supplied power and the third acted as the common ground. The driver device is used to adjust the intensity of blue and red light as well as the frequency and duty ratio, making it a flexible light source providing continuous or intermittent light and varying light intensity and quality (in terms of blue vs. red light).
The device is currently patent pending (Fang et al., 2001).

Plant materials and culture conditions. Single-node cuttings with leaf attached were excised from 28-d-old potato plantlets (Solanum tuberosum L. 'Kennebec') and explanted into 785-mL cylindrical polyvinyl chloride (PVC) vessels containing $50 \mathrm{~mL}$ of MS (Murashige and Skoog, 1962) medium supplemented with $20 \mathrm{~g} \cdot \mathrm{L}^{-1}$ sucrose and $8 \mathrm{~g} \cdot \mathrm{L}^{-1}$ agar. Vessels were secured with a transparent PVC cap with an air-exchange, 5-mm hole filled with cotton. Number of air exchanges of the vessel was $0.08 / \mathrm{h}$ as determined by the method described by Kozai et al. (1986). Each vessel had two openings connected to microporous membrane filters (pore size, $0.2 \mu \mathrm{m}$; Millex-FG50, Millipore, Billerica, Mass.) for $\mathrm{CO}_{2}$ concentration measurement.

Eight experimental treatments were designed and coded according to the sequence of type of light source (LED and TFL), methods to apply light (C-NF, IP180, IP720, and C-F60), duty ratio and photoperiod $(8,12$, 16, and 24; Table 1). A mean photosynthetic photon flux $(P P F)$ of $120 \pm 10 \mu \mathrm{mol} \cdot \mathrm{m}^{-2} \mathrm{~s}^{-1}$ (LI-190, LI-COR) and quantum ratios of blue $(400-500 \mathrm{~nm})$ over red light $(600-700 \mathrm{~nm})$ were 1.56 for both TFLs and LEDs systems. Treatments were arranged in a completely randomized design with the experiment repeated three times. The LEDSet was located above the cultural vessel at $1 \mathrm{~cm}$ apart and the TFL was at $30-\mathrm{cm}$ distance.

Data collection and statistical analysis. Plant height and fresh/dry weight of shoots and roots of the explants were destructively measured for each treatment of nine samples (three vessels) weekly for 4 weeks. The initial dry weight of the explants was derived as listed below:

$$
\mathrm{DW}=0.1 \times \mathrm{FW}+0.3 \quad\left(r^{2}=0.98\right)
$$

where DW and FW are the dry and fresh weight (in $\mathrm{mg}$ ) of the explants at day 0 . The equation was obtained from 20 samples dried in the oven at $105^{\circ} \mathrm{C}$ for $30 \mathrm{~min}$ and maintained at $60{ }^{\circ} \mathrm{C}$ for $24 \mathrm{~h}$. The average initial dry weight per explant was $1.29 \pm 0.39 \mathrm{mg}$. Explants were grown in a controlled environment at a temperature of 25 $\pm 2{ }^{\circ} \mathrm{C}$ and a relative humidity of $50 \% \pm 10 \%$. There were three explants per vessel and 12 vessels per treatment. Treatment means were analyzed using Duncan's multiple range test and orthogonal contrasts.

Energy consumption of each treatment was recorded using a $110 \mathrm{~V}$ AC power meter (1-18NTABA, Tatung Corp., Taiwan). For the LED system, sinks for power consumption were the $5 \mathrm{~V} \mathrm{AC} / \mathrm{DC}$ converter and two drivers with six LEDSets each. The power sinks for TFLs were two tubular lamps, each with one ballast. Total power consumption of LEDSets and driver was separated into static (SPC) and dynamic power consumption (DPC). DPC and SPC were determined using

$$
\mathrm{DPC}=\mathrm{f} \times \mathrm{C} \times \mathrm{V}_{\mathrm{CC}}^{2} \quad(\text { Sedra, 1991) }
$$

and

$$
\mathrm{SPC}=\mathrm{i} \times \mathrm{V}_{\mathrm{CC}} \times \text { Duty ratio }
$$


Table 1. Treatment, descriptions, plant height, and dry weight of potato plantlets in vitro grown $28 \mathrm{~d}$ in eight treatments.

\begin{tabular}{lcccccr}
\hline Treatment no. \& & Daily light-on & Plant height & \multicolumn{3}{c}{ Dry wt (DW) } & \\
\cline { 5 - 6 } treatment code $^{\mathrm{z}}$ & hours $^{\mathrm{y}}$ & $(\mathrm{mm})$ & Shoot & Root & Total & TDW/DAL $^{\mathrm{x}}$ \\
\hline 1. LED-CNF-100-8/16 & $8 \times 100 \%=8$ & $67.0 \mathrm{~d}^{\mathrm{w}}$ & $9.9 \mathrm{~d}$ & $2.2 \mathrm{e}$ & $12.1 \mathrm{e}$ & 3.5 \\
2. LED-CNF-100-12/112 & $12 \times 100 \%=12$ & $71.9 \mathrm{c}$ & $12.2 \mathrm{c}$ & $2.5 \mathrm{e}$ & $14.7 \mathrm{~d}$ & 2.8 \\
3. LED-IP180-50-24/0 & $24 \times 50 \%=12$ & $90.9 \mathrm{~b}$ & $13.4 \mathrm{c}$ & $3.1 \mathrm{~d}$ & $16.5 \mathrm{c}$ & 3.2 \\
4. LED-IP180-50-16/8 & $16 \times 50 \%=8$ & $81.7 \mathrm{~b}$ & $16.2 \mathrm{a}$ & $5.4 \mathrm{c}$ & $21.6 \mathrm{~b}$ & 6.2 \\
5. LED-IP1720-50-24/0 & $24 \times 50 \%=12$ & $88.7 \mathrm{~b}$ & $15.6 \mathrm{ab}$ & $6.5 \mathrm{~b}$ & $22.1 \mathrm{ab}$ & 4.2 \\
6. LED-IP720-50-16/8 & $16 \times 100 \%=8$ & $106.1 \mathrm{a}$ & $16.3 \mathrm{a}$ & $8.2 \mathrm{a}$ & $24.5 \mathrm{a}$ & 7.1 \\
7. TFL-CF60-100-16/8 & $16 \times 100 \%=16$ & $84.9 \mathrm{~b}$ & $15.2 \mathrm{ab}$ & $5.7 \mathrm{bc}$ & $20.9 \mathrm{~b}$ & 3.0 \\
8. TFL-CF60-100-8/16 & $8 \times 100 \%=8$ & $69.3 \mathrm{~d}$ & $10.0 \mathrm{~d}$ & $2.2 \mathrm{e}$ & $12.2 \mathrm{e}$ & 3.5
\end{tabular}

${ }^{\mathrm{z}} \mathrm{CNF}=$ continuous nonfluctuating light, IP180 and IP720 = intermittent pulse light at $180 \mathrm{~Hz}$ frequency [5.6-millisecond (ms) period] and $720 \mathrm{~Hz}$ frequency $(1.4-\mathrm{ms}$ period), respectively. CF60 = continuous fluctuating light at $60 \mathrm{~Hz}$ frequency (16.7-ms period). For continuous light (CNF treatments 1, 2, and CF treatments 7 and 8) and intermittent pulse light (IP treatments 3-6), the duty ratios are always $100 \%$ and $50 \%$, respectively. Photoperiod is in the form of light/dark hours. A full cycle of light/dark is $24 \mathrm{~h}$.

'Daily light-on hours $=$ duration of light period $\times$ duty ratio. The accumulated light per day equals 3.45, 5.18 , and $6.91 \mathrm{~mol} \cdot \mathrm{m}^{-2}$ when the "hours of light-on per day" equals 8,12 , and $16 \mathrm{~h}$, respectively. Daily accumulated light $=$ mean light intensity $\left(\mu \mathrm{mol} \cdot \mathrm{m}^{-2} \cdot \mathrm{s}^{-1}\right) \times$ light-on (hours/day $) \times 3600($ seconds/hour $) \times$ $10^{-6}\left(\mathrm{~mol}^{\prime} \mu \mathrm{mol}^{-1}\right)$.

${ }^{\mathrm{x}} \mathrm{TDW} / \mathrm{DAL}=$ total dry weight / daily accumulated light.

${ }^{w}$ Means within a column followed by the same letters are not significantly different at the 5\% level of Duncan's multiple range test.

where $\mathrm{f}=$ frequency; $\mathrm{C}=$ comparable capacitor of all circuits; and $\mathrm{i}=$ circuit current (in A) when voltage is at $\mathrm{V}_{\mathrm{CC}}$. Higher frequency consumed more power and lower duty ratio consumed less power.

In a given driver provided with preset voltage and current, values of $\mathrm{C}, \mathrm{V}_{\mathrm{CC}}$, and i were constants. LED with no frequency manipulation provided continuous light and required no extra power consumption in DPC term and the duty ratio in SPC term is $100 \%$.

The mean $\mathrm{CO}_{2}$ concentration inside the vessel $(\mathrm{Cv})$ and the culture room $(\mathrm{Cr})$ were measured during the light and dark period in each treatment on day 14 and 28 using an on line $\mathrm{CO}_{2}$ analyzer (CI-301, CID, Camas, Wash.). $\mathrm{CO}_{2}$ concentration measurement was taken $4 \mathrm{~h}$ after the initiation of the photoperiod, when $\mathrm{Cv}$ and $\mathrm{Cr}$ were considered to have reached steady state (Fujiwara et al., 1987) and the measurement period was set at 10

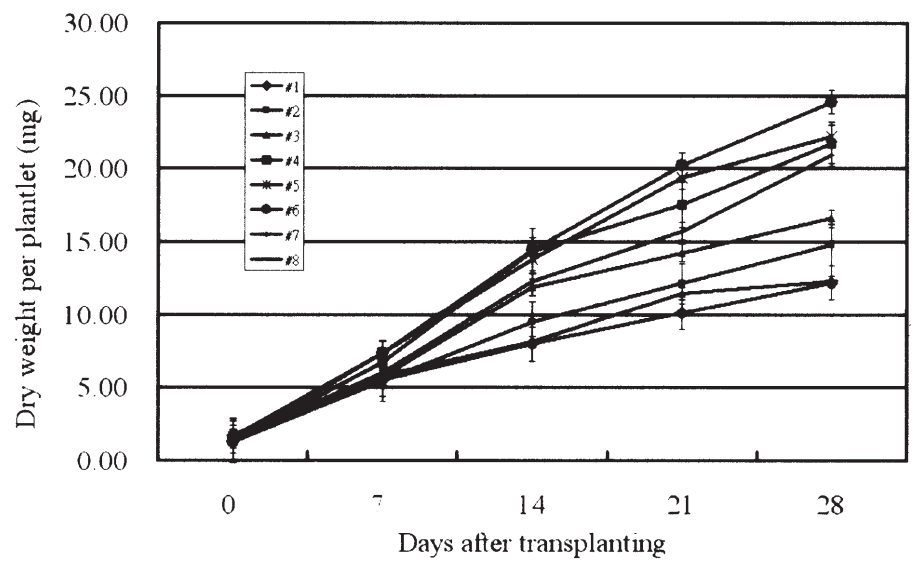

Fig. 4. Changes in dry weight per plantlet over time. Treatment $1=$ LED as light source with no frequency and 8-h light/16-h dark photoperiod. Treatment $2=$ LED as light source with no frequency and $12 / 12 \mathrm{~h}$ photoperiod. Treatment $3=\mathrm{LED}$ as light source with $180 \mathrm{~Hz}$ frequency, $50 \%$ duty ratio and 24/0 h photoperiod.Treatment $4=$ LED as light source with $180 \mathrm{~Hz}$ frequency, $50 \%$ duty ratio and $16 / 8 \mathrm{~h}$ photoperiod. Treatment $5=$ LED as light source with $720 \mathrm{~Hz}$ frequency, $50 \%$ duty ratio and 24/0 h photoperiod. Treatment $6=$ LED as light source with $720 \mathrm{~Hz}$ frequency, $50 \%$ duty ratio and $16 / 8 \mathrm{~h}$ photoperiod. Treatment $7=$ TFL as light source with $60 \mathrm{~Hz}$ frequency, $100 \%$ duty ratio and $16 / 8$ h photoperiod. Treatment $8=$ TFL as light source with $60 \mathrm{~Hz}$ frequency, $100 \%$ duty ratio and $8 / 16$ h photoperiod. light/8-h dark photoperiod) (Table 1). A 17\% improvement over treatment 7 might not seem significant if actual daily light-on hours were not considered.

Growth of potato plantlets, in terms of plant height and dry weight (DW) after $28 \mathrm{~d}$ was influenced by light frequency and can be best described by comparing treatments 6,1 , and 8 (Table 1). The daily light-on hours were similar $(8 \mathrm{~h})$ for these three treatments, yet treatment 6 had the greatest shoot/root/total DW and height with treatments 8 and 1 being the worst. DW of treatment 6 was $202.4 \%$ and $200.8 \%$ over treatments 8 and 1, respectively. Light utilization efficiency, in terms of DW over daily-accumulated light was 2.36 (7.1 vs. 3 ) and 2.06 (6.2 vs. 3) times greater, respectively, than in the control group. Height and shoot/root/total DW of plantlets grown using light treatments 1 and 8 were nonsignificant, indicating that the amount of accumulated light governed the growth of potato plantlets in vitro, regardless if LEDs (treatment 1) or TFLs (treatment 8) were used. The effects of treatments 1 and 8 on $\mathrm{CO}_{2}$ concentration inside the vessel were similar (Fig. 5).

$\mathrm{CO}_{2}$ concentration of the culture room was maintained at $438.4 \pm 1.9 \mu \mathrm{mol} \cdot \mathrm{mol}^{-1}$. The difference in $\mathrm{CO}_{2}$ concentration between the interior $(\mathrm{Cv})$ and exterior $(\mathrm{Cr})$ culture environment $(\Delta \mathrm{C}=\mathrm{Cv}-\mathrm{Cr})$ on days 14 (thin line) and 28 (thick line) under different treatments were most determined by the length of the dark treatment (Fig. 5).

$\mathrm{CO}_{2}$ concentration inside the vessel reached saturation when the dark period was longer than $12 \mathrm{~h}$ (treatments 1 and 8). The accumulated $\mathrm{CO}$ during darkness was consumed $2 \mathrm{~h}$ after the light period started among treatments 4 and 6 . Treatment 6 had the highest and lowest $\Delta \mathrm{C}$ during dark and light period, respectively. The only difference of these two treatments was the frequency. A similar observation was found with treatments 3 and 5. Treatments with higher frequency had lower $\Delta \mathrm{C}$ value. The total daily light-on hours for treatments 2 and 3 were the same, but the variation of $\Delta \mathrm{C}$ throughout the day was totally different, suggesting that $\mathrm{CO}_{2}$ concentration inside the vessel was governed by existence of the continuous darkness. During the light periods, consumption of $\mathrm{CO}_{2}$ was obvious in all treatments.

Fujiwara (1992) reported that cultures grow and develop dominantly depending on sucrose concentration in the culture medium $(\approx 10 \mathrm{~d}$ with $25 \mathrm{~g} \cdot \mathrm{L}^{-1}$ sucrose concentration). In vessels void of explants but with MS medium, $\Delta \mathrm{C}$ was always positive $\left(16.0 \pm 2.9 \mu \mathrm{mol} \cdot \mathrm{mol}^{-1}\right)$ regardless of photoperiod treatment. This indicates that the medium influences photosynthetic measurements inside the vessel, but can be neglected due to its constant small value and regardless of the existence of light.

Comparing treatments 3 (24/0 photoperiod) and 4 (16/8 photoperiod), the growth rate of potato plantlets under continuous light was similar to those illuminated with $16 \mathrm{~h}$ under intermittent light (Fig. 6). A similar result was observed between treatments 5 and 6 . Potato plantlets receiving $8 \mathrm{~h}$ of continuous darkness grew better, indicating that the dark period 

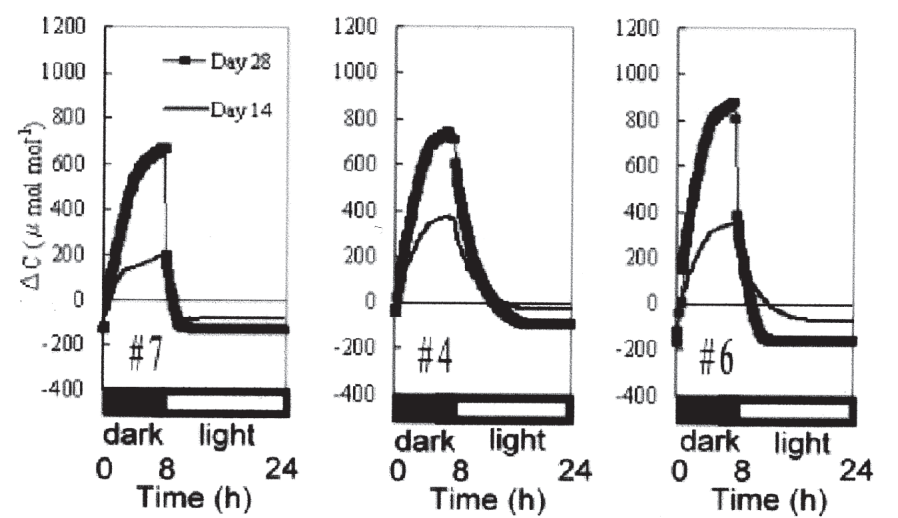

Table 2. Analysis of variance summary for the total dry weight of potato plantlets. Data were analyzed using procedures for a completely randomized design with treatment comparisons made using orthogonal contrasts.
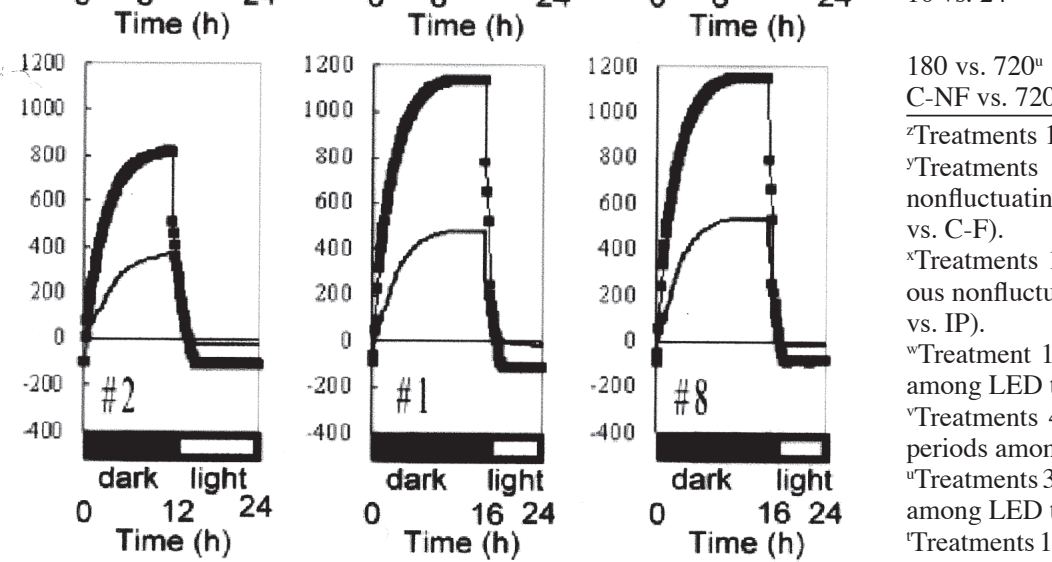

\begin{tabular}{|c|c|c|c|c|}
\hline Source & DF & Sums of squares & Mean square & F-value \\
\hline Treatment & 7 & 1458.048 & 208.292 & $11.63^{* * *}$ \\
\hline Error & 64 & 1146.008 & 17.906 & --- \\
\hline Corrected total & 71 & 2604.05 & --- & --- \\
\hline \multicolumn{5}{|c|}{ Contrasts of group 1} \\
\hline LED vs. TFL ${ }^{z}$ & 1 & 57.247 & 57.247 & $3.2^{\mathrm{Ns}}$ \\
\hline $\mathrm{C}-\mathrm{NF}$ vs. $\mathrm{C}-\mathrm{F}^{\mathrm{y}}$ & 1 & 88.172 & 88.172 & $4.92^{\mathrm{Ns}}$ \\
\hline C-NF vs. IP & 1 & 727.067 & 727.067 & $40.6^{* *}$ \\
\hline \multicolumn{5}{|c|}{ Contrasts of group 2} \\
\hline 8 vs. $16^{\mathrm{w}}$ & 1 & 717.809 & 717.809 & $40.09^{* *}$ \\
\hline 16 vs. $24^{v}$ & 1 & 152.012 & 152.012 & $8.81^{* *}$ \\
\hline \multicolumn{5}{|c|}{ Contrasts of group 3} \\
\hline 180 vs. $720^{u}$ & 1 & 163.072 & 163.072 & $9.11^{* *}$ \\
\hline C-NF vs. $720^{t}$ & 1 & 884.269 & 884.269 & $49.38^{* * *}$ \\
\hline
\end{tabular}

'Treatments $1,2,3,4,5$, and 6 vs. treatments 7 and 8 .

yTreatments 1 and 2 vs. treatments 7 and 8 (Comparison on continuous nonfluctuating light of LEDs vs. continuous fluctuating light of TFLs: C-NF vs. C-F).

xTreatments 1 and 2 vs. treatments 3, 4, 5, and 6 (Comparison on continuous nonfluctuating light of LEDs vs. intermittent/pulse light of LEDs: C-NF vs. IP).

wTreatment 1 vs. treatments 4 and 6 (Comparison on various light periods among LED treatments: $8 \mathrm{~h}$ vs. $16 \mathrm{~h}$ ).

vTreatments 4 and 6 vs. treatments 3 and 5 (Comparison on various light periods among LED treatments: $16 \mathrm{~h}$ vs. $24 \mathrm{~h})$.

uTreatments 3 and 4 vs. treatments 5 and 6 (Comparison on various frequencies among LED treatments: $180 \mathrm{~Hz}$ vs. $720 \mathrm{~Hz})$.

'Treatments 1 and 2 vs. treatments 3 and 4 (Comparison on various frequencies among LED treatments: C-NF vs. $180 \mathrm{~Hz}$ ).
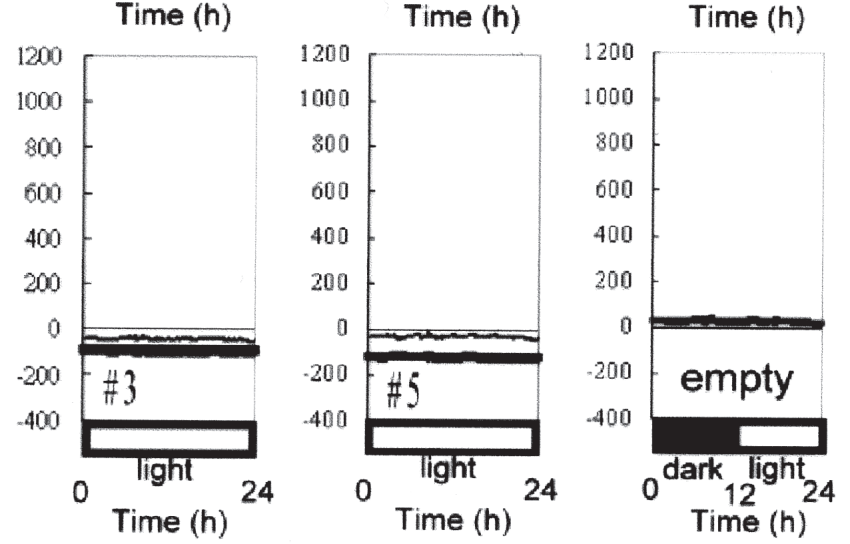

Ns, *** Nonsignificant or significant contrast at the 0.01 level.

Fig. 5. The difference in $\mathrm{CO}_{2}$ concentrations between the inside and outside of the vessel 14 and $28 \mathrm{~d}$ after treatments. For other treatment symbols, see Table 1 and text.

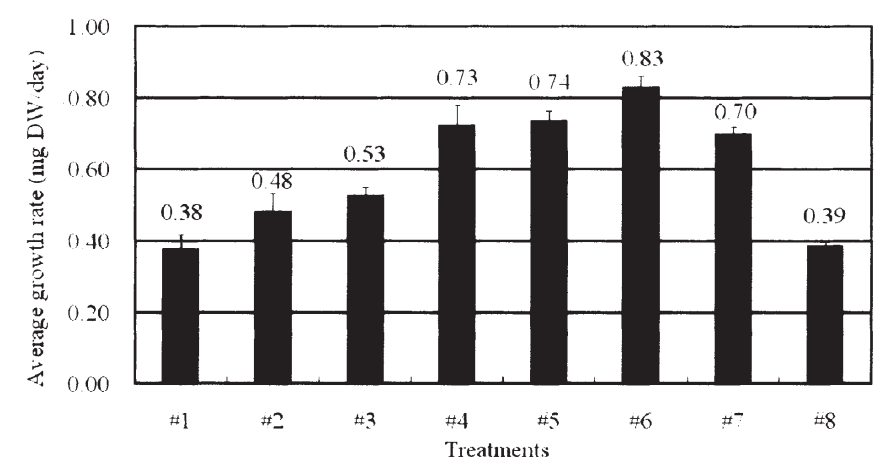

Fig. 6. Average growth rate of potato plantlets in all treatments. Treatment $1=$ LED as light source with no frequency and 8-h light/16-h dark photoperiod. Treatment $2=$ LED as light source with no frequency and 12-h light/12-h dark photoperiod. Treatment 3 = LED as light source with $180 \mathrm{~Hz}$ frequency, $50 \%$ duty ratio and 24-h light/0-h dark photoperiod. Treatment $4=$ LED as light source with $180 \mathrm{~Hz}$ frequency, 50\% duty ratio and 16-h light/8-h photoperiod. Treatment 5 = LED as light source with 720 $\mathrm{Hz}$ frequency, $50 \%$ duty ratio and 24-h light/0-h dark photoperiod. Treatment $6=\mathrm{LED}$ as light source with $720 \mathrm{~Hz}$ frequency, $50 \%$ duty ratio and 16 -h light $/ 8$-h dark photoperiod. Treatment $7=$ TFL as light source with $60 \mathrm{~Hz}$ frequency, $100 \%$ duty ratio and 16 -h light $/ 8$-h dark photoperiod. Treatment $8=\mathrm{TFL}$ as light source with $60 \mathrm{~Hz}$ frequency, $100 \%$ duty ratio and 8 -h light/16-h dark photoperiod.

increased the demand for new assimilation.

Potato plantlets grew better using high frequency $(720 \mathrm{~Hz})$ compared to lower frequency $(180 \mathrm{~Hz})$ with similar accumulated light (Table 1). However, there is an upper limit on frequency due to the fact that plants receiving treatments 1 and 2 , under continuous-nonfluctuating (C-NF) light, did not grow as well as those irradiated with intermittent light (treatments $3,4,5$, and 6 ). Note that the frequency of a C-NF light is infinity.

Total dry weights were analyzed using orthogonal contrasts. Three groups of contrast were conducted, including group 1: means to provide light and types of light source (contrasts listed in the first column of Table 2 with the superscripts of $x, y$, and $z$ ); group 2: light period (with the superscripts of $\mathrm{w}$ and $\mathrm{v}$ ); and group 3: frequency (with the superscripts of $\mathrm{u}$ and $\mathrm{t}$ ).

As shown in the first two rows of the group 1 contrast, both LED vs. TFL and C-NF vs. C-F contrasts had no significant differences (Table 2). Note that TFL and C-F represent the same treatments ( 7 and 8). These contrasts revealed the fact that the growth of potato plantlets in vitro had no difference under the continuous light no matter the photons were from LED or TFL. Also, note that LED (treatments 1 to 6) represents C-NF (treatments 1 and 2) plus IP (treatments 3 to 6) and C-NF showed great significant difference with IP as shown in the third row of group 1 contrast. This contrast revealed that means to apply light has great significant difference when using LED.

In order to compare various means in providing LED light, treatments of TFL (treatments 7 and 8) were excluded in the contrasts 
Table 3. Effects of various treatments on power consumption, dry weight increment, and conversion efficiency. For description of treatments, see Table 1 and text.

\begin{tabular}{lcccc}
\hline $\begin{array}{l}\text { Treatment } \\
\text { number }^{2}\end{array}$ & $\begin{array}{c}\text { Relative power } \\
\text { consumption } \\
\text { per vessel, (A) }\end{array}$ & $\begin{array}{c}\text { Relative dry wt } \\
\text { increment } \\
\text { per vessel, }(\mathrm{B})\end{array}$ & $\begin{array}{c}\text { Power conversion } \\
\text { efficiency } \\
(\mathrm{B} / \mathrm{A})\end{array}$ & $\begin{array}{c}\text { Light conversion } \\
\text { efficiency } \\
\left(\mathrm{mg}^{\circ} \mathrm{mol}^{-1} \cdot \mathrm{m}^{-2}\right)\end{array}$ \\
\hline 1 & 0.96 & 0.54 & 0.56 & 0.11 \\
2 & 1.05 & 0.69 & 0.66 & 0.09 \\
3 & 1.74 & 0.75 & 0.43 & 0.10 \\
4 & 1.17 & 1.03 & 0.88 & 0.21 \\
5 & 8.34 & 1.06 & 0.13 & 0.14 \\
6 & 5.55 & 1.19 & 0.21 & 0.24 \\
$7 \mathrm{y}$ & 1.00 & 1.00 & 1.00 & 0.10 \\
8 & 0.56 & 0.55 & 0.98 & 0.11 \\
\hline
\end{tabular}

${ }^{2}$ Treatment 1 = LED as light source with no manipulation on frequency and $8 \mathrm{~h}$ light $/ 16 \mathrm{~h}$ dark photoperiod. Treatment $2=\mathrm{LED}$ as light source with no manipulation on frequency and $12 / 12 \mathrm{~h}$ photoperiod. Treatment $=\mathrm{LED}$ as light source with $180 \mathrm{~Hz}$ frequency, 50\% duty ratio and 24/0 h photoperiod. Treatment $=$ LED as light source with $180 \mathrm{~Hz}$ frequency, $50 \%$ duty ratio and 16/8 photoperiod. Treatment = LED as light source with $720 \mathrm{~Hz}$ frequency, $50 \%$ duty ratio and 24/0 h photoperiod. Treatment $6=\mathrm{LED}$ as light source with $720 \mathrm{~Hz}$ frequency, $50 \%$ duty ratio and 16/8 photoperiod;. Treatment $7=$ TFL as light source with $60 \mathrm{~Hz}$ frequency, $100 \%$ duty ratio and $16 / 8 \mathrm{~h}$ photoperiod. Treatment $8=$ TFL as light source with $60 \mathrm{~Hz}$ frequency, $100 \%$ duty ratio and $8 / 16 \mathrm{~h}$ photoperiod.

${ }^{\mathrm{y}}$ Control group.

of groups 2 and 3. Significant differences were found in the contrasts of group 2 among 8-, 16- and 24-h light periods and the contrasts of group 3 among 180, $720 \mathrm{~Hz}$ and C-NF treatments. The contrast of C-NF vs. 720 showed the greatest difference among all contrasts.

Treatments $1,4,6$, and 8 had the same daily light-on duration $(8 \mathrm{~h})$ as shown in the second column of Table 1 . However, the relative dry weight increment (third column in Table 3) ranged from 0.54 to 1.19 . These variations indicated that how the $8 \mathrm{~h}$ of light distributed to the plant is extremely important.

Relative power consumption (RPC) per vessel in each treatment varied over the $28 \mathrm{~d}$ (second column, Table 3). Treatments 1 and 2 had no manipulation on frequency, thus no extra energy was required in frequency generation and no DPC required when providing current. Frequency was the reason that the RPC of treatment 3 was larger than the value of treatment 2. Treatments 3 and 4 were both at $180 \mathrm{~Hz}$, hence the difference on RPC was due to differences in photoperiod. The same observation can be found in treatments 5 and 6 . The RPC of treatments 5 and 6 were much greater than treatments 3 and 4, respectively, due to differences in frequency. Higher frequencies require more power to run due to high DPC value.

The power conversion efficiency (PCE), defined as the relative dry weight increment vs. relative power consumption, was high for treatments 7 and 8 (Table 3 ). This can be explained by the fact that one TFL $(120 \mathrm{~cm}$ length $)$ can be used for at least 30 vessels (arranged in three lines), leading to a low RPC value (Table 3). Explants grown in treatment 6 (LED-IP72050-16/8) had the highest relative dry weight increment, yet had the poor PCE due to high energy consumption at high frequency. Among LED treatments, treatment 4 (LED-IP180-50$16 / 8$ ) was the best choice with similar growth rate in comparison with traditional fluorescent lamp system. The RPC and relative dry weight increment of treatment 4 were $17 \%$ and $3 \%$ over the control group (treatment 7), respectively. Light conversion efficiency (LCE) defined as the ratio of chemical energy contained in dry mass to light energy provided was also calculated (Table 3). LED with adjusted frequency (treatments 4 and 6) and 8-h dark period had higher LCE value than other treatments. LED with no frequency (treatments 1 and 2) and with frequency but no dark period (treatments 3 and 5) had similar LCE value as TFLs.

In two separate growth rooms using TFLs and LEDs as artificial light sources, the difference of cost on heat removal would be big. The cost to remove heat can be saved when LEDs are used and the savings should be able to compensate for the $17 \%$ difference of illuminating power consumption (comparing treatments 4 and 7). This would lead one to conclude that it is possible to save electricity without sacrificing the growth rate of potato plantlets using LEDs when costs on illumination and heat removal are both considered.

Effects of ethylene on the fresh and dry weights of the plantlet were not examined in this study, because ethylene was found not to have significant effects on fresh and dry weights of potato plantlets (Jackson et al., 1991). However, research is needed on the effects of accumulated ethylene on plantlet morphology. Moreover, more efficient ways of applying high frequency on LEDs and the effects of higher frequency $(>1000 \mathrm{~Hz})$ LEDs on the photomixotrophic and photoautotrophic growth of plantlets are needed for further study.

\section{Literature Cited}

Brown, H.T. and F. Escombe. 1905. Researches on some of the physiological processes of green leaves, with special reference to the interchange of energy between the leaf and its surroundings. Proc. R. Soc. Lond. Ser. B. Biol. Sci. 76:29-111.

Emerson, R. and W. Arnold. 1932. A separation of the reactions in photosynthesis by means of intermittent light. J. Gen. Physiol. 15:391-420.

Fang, W., R.C. Jao, and D.H. Lee. 2003. Artificial lighting apparatus for young plants using light emitting diodes as light source. U.S. patent no.: US64743838 B2 and US 6554450 B2.1

Fujiwara, K., T. Kozai, and I. Watanabe. 1987. Measurement of carbon dioxide gas concentration in closed vessels containing tissue cultured plantlets and estimates of net photosynthetic rates of plantlets. J. Agr. Meteorol. 43(1):21-30.

Fujiwara, K., S. Kira, and T. Kozai. 1992. Time course of $\mathrm{CO}_{2}$ exchange of potato cultures in vitro with different sucrose concentrations in the culture medium. J. Agr. Meteorol. 48(1):49-56.

Hashimoto, Y., Y. Yi, F. Nyunoya, Y. Anzai, H. Yamazaki, S. Nakayama, and A. Ikeda. 1988. Vegetable growth as affected by on-off light intensity developed for vegetable factory. Acta Hort. 229:259-264.

Jackson, M.B.,A.J. Abbott, A.R. Belcher, K.C. Hall, R. Butler, and J. Cameron. 1991. Ventilation in plant tissue cultures and effects of poor aeration on ethylene and carbon dioxide accumulation, oxygen depletion and explant development. Ann. Bot. 67:229-237.

Jao, R.C. and W. Fang. 2001. Development of a flexible lighting system for plant related research using super bright red and blue light emitting diodes. Acta Hort. 578:133-139.

Jao, R.C. and W. Fang. 2003. An adjustable light source for photo-phyto related research and young plant production. Appl. Eng. Agr. 19(5):601-608.

Kozai, T., K. Fujiwara, and I. Watanabe. 1986. Effects of stoppers and vessels on gas exchange rates between inside and outside of vessels closed with stoppers. J. Agr. Meteorol. 42:119-127.

Murashige, T. and F. Skoog. 1962. Arevised medium for rapid growth and bioassays with tobacco tissue cultures. Physiol. Plant. 15:473-497.

Nedbal L., V. Tichy, and F.H. Xiong. 1996. Microscopic green algae and cyanobacteria in highfrequency intermittent light. J. Appl. Phycol. 8:325-333.

Rabinowitch, E.I. 1956. Photosynthesis and related processes, Vol. 2, part 2. Interscience Publ., New York.

Sager, J.C., W.H. Klein, and J.L. Edwards. 1980 Intermittent irradiation utilization within a plant canopy. ASAE Paper No. 80-4043. Amer. Soc. Agr. Eng., St. Joseph, Mich.

Sager, J.C. and W. Giger. 1980. Re-evaluation of published data on the relative photosynthetic efficiency of intermittent and continuous light. Agr. Meteorol. 22:289-302.

Sedra A.S. and K.C. Smith, 1991. Microelectronic circuits. 3rd ed. Saunders College Publ., Philadelphia.

Tennessen, D.J., R.J. Bula, and T.D. Sharkey. 1995. Efficiency of photosynthesis in continuous and pulsed light emitting diode irradiation. Photosynthetic Res. 44:261-269.

Warburg, O. 1919. Über die Geschwindigkeit der photochemischen Kohlensäurezersetzung in lebenden Zellen. Biochem. Z. 100:230-270.

Weller, S. and J. Franck. 1941. Photosynthesis in flashing light. J. Phys. Chem. 45:1359-1373. 